\title{
Chasing the addicted engram: identifying functional alterations in Fos-expressing neuronal ensembles that mediate drug-related learned behavior
}

\author{
Leslie R. Whitaker ${ }^{1}$ and Bruce T. Hope ${ }^{2}$ \\ ${ }^{1}$ Office of the Scientific Director; Intramural Research Program, National Institute on Drug Abuse, National Institutes of Health, \\ Baltimore, Maryland 21224, USA; ${ }^{2}$ Neuronal Ensembles in Addiction Section; Behavioral Neuroscience Research Branch, Intramural \\ Research Program, National Institute on Drug Abuse, National Institutes of Health, Baltimore, Maryland 21224, USA
}

\begin{abstract}
Given that addiction has been characterized as a disorder of maladaptive learning and memory, one critical question is whether there are unique physical adaptations within neuronal ensembles that support addiction-related learned behavior. The search for the physical mechanisms of encoding these and other memories in the brain, often called the engram as a whole, continues despite decades of research. As we develop new technologies and tools that allow us to study cue- and behavior-activated Fos-expressing neuronal ensembles, the possibility of identifying the engrams of learning and memory is moving into the realm of reality rather than speculation. It has become clear from recent studies that there are specific functional, electrophysiological alterations unique to Fos-expressing ensemble neurons that may participate in encoding memories. The ultimate goal is to identify the addicted engram and reverse the physical changes that support this maladaptive form of learning.
\end{abstract}

\begin{abstract}
Addiction can be conceptualized as a disorder of learning and memory. Indeed, environmental stimuli such as cues and contexts become strongly associated with drugs of abuse after repeated exposure (Wikler 1973; Goldberg 1976; Stewart et al. 1984; O'Brien et al. 1986; Robinson and Berridge 1993; Siegel 1999; Crombag et al. 2008). Subsequent exposure to these drug-paired stimuli can drive craving and ultimately relapse to drug seeking behavior. Given that this maladaptive form of learning is a powerful driver of relapse, understanding the neurobiological correlates of these associations will be a critical step in reversing this learning and will ultimately aid in identifying novel targets for treatment. The majority of research examining neurobiological correlates of addiction-related behavior has focused on identifying neuroadaptations that occur throughout the general neuronal population in a brain region of interest (Hyman et al. 2006; Koob 2006; Bowers et al. 2010; Scofield et al. 2016). However, associative learning relies on functional alterations within sparsely distributed populations of neurons, commonly referred to as "neuronal ensembles," that are selected by specific cues during learning (Hebb 1949; Pennartz et al. 1994; Nicolelis et al. 1997; Buzsaki 2004; Schwindel and McNaughton 2011; Lansink et al. 2012; Cruz et al. 2015). Recent technologies now permit us to identify and characterize ensembles that are activated enough to activate the immediate early gene Fos. However, this review is not about the technologies used; for reviews focused on the Fos-based technologies, see (Garner and Mayford 2012; Cruz et al. 2013; Kawashima et al. 2013, 2014; Ramirez et al. 2013a; Mayford and Reijmers 2015; Tonegawa et al. 2015; Warren et al. 2017). Here we focus on electrophysiological alterations within Fos-expressing neuronal ensembles in appetitive learned behaviors related to addiction research (Cruz et al. 2015). For reviews focused on neuronal ensembles in fear conditioning, readers can refer to (Garner and Mayford 2012; Cruz et al. 2013; Kawashima et al. 2013, 2014; Ramirez et al. 2013a; Warren et al. 2017).
\end{abstract}

\section{Corresponding author: leslie.ramsey@nih.gov}

Article is online at http://www.learnmem.org/cgi/doi/10.1101//m.046698.117.

\section{Why study Fos-expressing neuronal ensembles in the context of addiction?}

Hebb postulated in 1949 that memories could be encoded in "cell assemblies" or small groups of sparsely distributed neurons (Hebb 1949). Early support for this idea came from in vivo recording data demonstrating ensemble-based coding of location in hippocampus (Mountcastle 1957; O'Keefe 1976; Wilson and McNaughton 1993). Early ensemble-based coding was also demonstrated in the nucleus accumbens, a brain region known to play a critical role in reward-based learning (Carelli et al. 1993; Pennartz et al. 1994). Only a minority of neurons in the accumbens are active during drug seeking (Carelli and Wightman 2004), and separate populations are active in response to drug versus natural reward-related cues (Carelli et al. 2000). Although in vivo recording data support the neuronal ensemble hypothesis, these data are still correlational and not a direct demonstration of neuronal ensembles playing a causal role in mediating behavior.

For many years, expression of the immediate early gene products Fos mRNA and protein had been used to label neurons that were strongly activated during behaviors used in addiction research (Morgan and Curran 1991; Kawashima et al. 2014; Cruz et al. 2015). Based on this premise, Koya et al. (2009) used FoslacZ transgenic rats to coexpress $\beta$-galactosidase in strongly activated Fos-expressing neurons in a context-specific sensitization model. Daun02 injections into nucleus accumbens selectively ablated only the $\beta \mathrm{Gal} /$ Fos-expressing neurons that were previously activated during exposure to the cocaine-paired context attenuated expression of the learned behavior, but not when Daun02 ablated a different set of Fos-expressing neurons activated by exposing the rats to a distinct drug-unpaired context. This indicated that the environmental context activates specific Fos-expressing neuronal ensembles that mediate the specific learned behavior.

This is a work of the US Government. 
Since 2009, the Daun02 inactivation procedure has been used to inactivate Fos-expressing neuronal ensembles in different prefrontal cortex areas, nucleus accumbens, striatum, and amygdala and found causal roles for these ensembles in the expression of learned behaviors related to heroin (Bossert et al. 2011; Fanous et al. 2012), cocaine (Cruz et al. 2014), methamphetamine (Caprioli et al. 2017), ethanol (Pfarr et al. 2015; de Guglielmo et al. 2016) nicotine (Funk et al. 2016), and food (Suto et al. 2016; Warren et al. 2016; Whitaker et al. 2017). These ensembles may be involved in encoding the learned task itself (e.g., lever pressing) or in the learned motivation to perform the task, such as learning which cues inform the animal when it is appropriate or inappropriate to perform the task. Overall, whether encoding the task itself or the motivation to perform the task, the cellular mechanisms for encoding information within these neuronal ensembles are likely to be fundamentally the same.

A number of other transgenic, viral, and chemogenetic strategies based on activation of the Fos promoter have been used to manipulate these small populations of strongly active neurons and assess their role in learned behaviors in the addiction and fear conditioning fields (Garner and Mayford 2012; Cruz et al. 2013; Guenthner et al. 2013; Kawashima et al. 2013, 2014; Ramirez et al. 2013a; Warren et al. 2017). Most of these systems used the Fos promoter to drive expression of other proteins of interest (e.g., GFP, LacZ, tTA) to identify, manipulate and characterize the Fos-expressing neuronal ensembles (Reijmers et al. 2007; Liu et al. 2012; Cruz et al. 2013; Guenthner et al. 2013; Ramirez et al. 2013b; Pfarr et al. 2018). However, some strategies used promoters from other neural activity-dependent IEGs, such as Arc (Guenthner et al. 2013) and FosB (Engeln et al. 2016) or the synthetic promoter SARE (Kawashima et al. 2013) to identify and manipulate activated neuronal ensembles in learned behaviors. Nevertheless, all the studies regarding addiction related ensembles and engrams described below were based on neuronal ensembles identified by activation of the Fos promoter.

\section{Neuronal ensembles and engrams}

The term neuronal ensemble (or cell assembly) has been used to define small percentages of sparsely distributed neurons that undergo coordinated activation during behavior or stimuli presentation. When using in vivo electrophysiology recordings, neuronal ensembles can be populations of neurons that fire acutely with coordinated population firing rates and phase synchronization during ongoing behavior (Russo and Durstewitz 2017) without the necessity for learning or memory-related alterations. Since the term "engram" or "mneme" is defined as the memory trace, or the long-lasting, physical mechanism that encodes a learned association (Semon 1921; Eichenbaum 2016), then this acute activation during behavior is not the equivalent of the engram. Neuronal ensembles can be temporarily active during information processing with without long-term alterations.

We hypothesize that Fos-expressing ensembles comprise a small subset of the acutely activated ensembles that are detected using in vivo electrophysiology. Please see a more comprehensive discussion in (Cruz et al. 2013, 2015). We and others hypothesize that Fos induction in these neurons requires strong persistent activation of the neurons. The most strongly activated neurons cross a threshold when sufficient levels of calcium influx activate the ERK/ MAPK pathway that phosphorylates transcription factors on the Fos promoter to enable transcription (Morgan and Curran 1991; Brami-Cherrier et al. 2009; Cahill et al. 2014). This high activity threshold for Fos induction may explain the discrepancy between the low percentages of neurons detected using Fos expression and the higher percentages of ensemble-related neurons detected using in vivo electrophysiology. Only the most strongly and persistently activated neurons become part of the Fos-expressing ensemble. Based on the fact that selective Daun02-mediated ablation of Fos-expressing ensembles alters recall of memories in addiction research (Cruz et al. 2015), it appears that the neural activity thresholds seem to be similar for Fos expression and for recruiting a neuron into a persistent ensemble that mediates learned behaviors in addiction research.

In the search for an "addiction engram," it is important to be even more precise about what we are seeking. Daun02 inactivation and other related technologies suggest that Fos-expressing neurons in a given region of interest contain some alterations that allow them to be part of the engram. However, the Fos-expressing neurons per se do not necessarily constitute the engram. More precisely, the engram is the set of long-lasting molecular and cellular alterations (e.g., changes in synaptic efficacy) that are induced within these neurons during learning that alters the neurons' responses to specific afferent inputs to encode a memory.

In light of these definitions, most of the work with Fos-expressing ensembles in behavior has only identified Fos-expressing neurons that are "involved" in mediating a memory (Han et al. 2007; Reijmers et al. 2007; Bossert et al. 2011; Fanous et al. 2012; Liu et al. 2012; Cruz et al. 2014; Hsiang et al. 2014; Redondo et al. 2014; Pfarr et al. 2015; Ramirez et al. 2015; de Guglielmo et al. 2016; Funk et al. 2016; Suto et al. 2016; Warren et al. 2016; Caprioli et al. 2017). Most of these studies have not identified the actual engrams or alterations induced within these neurons that physically store the memories. Thus, the critical question now is what specific functional and physical changes were induced within the neuronal ensembles that drive learned behavior? New viral and transgenic methods have permitted the investigation of such questions (Barth et al. 2004; Reijmers et al. 2007; Koya et al. 2009; Cifani et al. 2012). Again, most of these technologies have relied on the Fos promoter as an indicator of strong neuronal activation to identify activated ensemble neurons (Morgan and Curran 1986; Cruz et al. 2015). Here we focus on electrophysiological alterations in Fos-expressing ensembles that may contribute functionally to the engram in animal models used in drug addiction research.

\section{Electrophysiological alterations}

The advent of new technologies permitting targeted recording from activity-dependent ensemble neurons has afforded the opportunity to determine specific functional, electrophysiological alterations within cells strongly activated by a particular event or experience. Both intrinsic and synaptic properties of ensemble neurons are beginning to be characterized (Fig. 1). We focused on neuronal ensembles within the nucleus accumbens and prefrontal cortex since these regions are known to be important for addiction-related learned behaviors (Peters et al. 2009; Feltenstein and See 2013; Marchant et al. 2015).

\section{Synaptic alterations}

The first demonstration of glutamatergic synaptic plasticity specific to Fos-expressing neurons identified an increase in silent synapses (synapses that contain functional NMDA but no functional AMPA receptors) (Koya et al. 2012). This study used FosGFP mice (Barth et al. 2004) to identify ensemble neurons within the nucleus accumbens following cocaine-induced locomotor sensitization. A follow-up study determined that silent synapses in NAc ensembles arose in a context-specific manner such that only animals trained and tested in the same context showed an increase in silent synapses (Whitaker et al. 2016). Previous work examining global neuroadaptations within the NAc also identified an up-regulation of silent synapses in the general population of neurons regardless of 


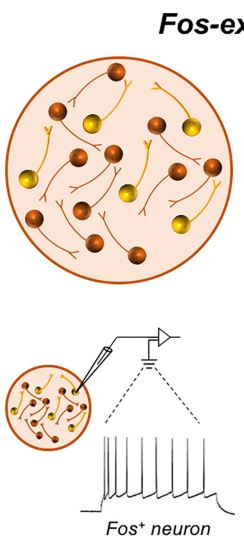

Fos-expressing neuronal ensembles

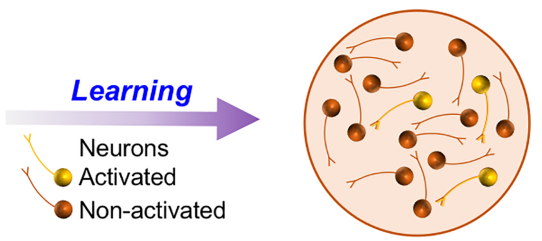

Intrinsic plasticity

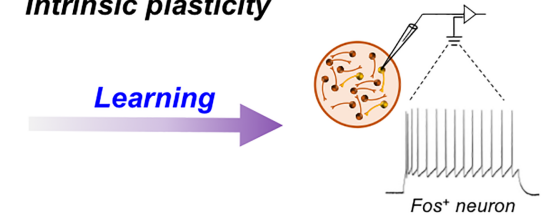

Synaptic plasticity

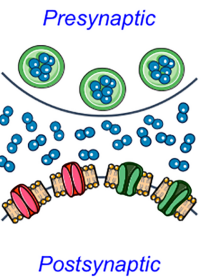

study using FosGFP mice showed that following exposure to a context previously paired with cocaine, there was a significant difference in firing properties of FosGFP+ and FosGFP- neurons (Ziminski et al. 2018). The effect was due to suppression of firing activity in the FosGFP- neurons. This difference was not present when mice were exposed to the saline-paired context suggesting that this change in firing may be important for the encoding of the learned association between cocaine and the locomotor chamber. A similar effect was found in an earlier study examining changes in prefrontal cortex firing activity in FosGFP rats following operant food self-administration training. In this study, FosGFP+ neurons showed increased firing whereas FosGFP- neurons suppressed their firing activity when injected somatically with depolarizing current (Whitaker et al. 2017). Taken together, these data support the idea that ensemble and nonensemble neurons together modulate the gain of the system such that the signal from ensemble neurons is given preference over signal from nonensemble neurons. Such a mechanism allows for increased signal to noise ratio in relevant brain regions that may contribute to encoding of learned associations. An important question that remains is how to reconcile findings reported in Fos-expressing ensembles as compared to the general population of neurons within a given brain region. Fos-expressing ensembles comprise a small percentage of cells within a particular brain region, encompassing between 2\%-10\% of neurons (Koya et al. 2009; Fanous et al. 2013; Cruz et al. 2014; Warren et al. 2016; Whitaker et al. 2016). Therefore, it is most likely that a cell selected at random within a particular brain region will be one of the nonactivated or weakly activated neurons and not a part of the neuronal ensemble. So global adaptation within randomly recorded cells are most likely to reflect the general trend within the Fos-negative population of neurons. Thus far there have been two studies in which Fos-negative neurons display opposite effects of Fos-positive neurons after behavioral training, but it remains to be seen whether this effect will generalize across different behaviors, brain regions, and cell types.

\section{The role of the SK channel in Fos-expressing ensembles and nonensembles}

An interesting potential player that has emerged from the literature on activity-dependent ensembles that mediate learned associations is the small conductance calcium-activated potassium channel. Disterhoft and colleagues found that neuronal excitability increases in CA1 pyramidal neurons following trace eyelid conditioning via a reduction in SK currents (Disterhoft et al. 1988; Moyer et al. 1996). Furthermore, the SK channel is known to interact with the NMDA receptor (Faber et al. 2005; Ngo-Anh et al. 2005), which is critical for many different types of learning and memory (Morris et al. 1986), and is necessary for the induction of many forms of long term potentiation (Bliss and Collingridge 1993). More recently, the SK channel has been implicated in drug-related associative learning. Hopf et al. described a reduction in SK channel function following withdrawal from alcohol seeking that led to increased excitability in randomly selected nucleus accumbens neurons (Hopf et al. 2010). More recently, Ziminski et al. (2018) discovered a reduction in the magnitude of the medium AHP in Fos-expressing neurons of nucleus accumbens core after cocaine conditioned locomotion, which may suggest a change in SK channel expression or function. Interestingly, SK channels were down-regulated in Fos-negative neurons of the medial PFC following operant food self-administration (Whitaker et al. 2017). While it is clear that the SK channel is an important modulator of excitability and a frequent target in studies of associative learning, its role in activity-dependent ensembles and addiction is yet to be explored. 


\section{Technical considerations}

Fos-expressing neuronal ensembles in addiction research are comprised of a heterogeneous population of cell types that reflect the general make-up of the brain region examined. Colabeling with RNAscope in situ hybridization or immunohistochemistry have found that Fos-expressing cortical ensembles were approximately 90\% glutamatergic and 10\% GABAergic, in line with the overall composition of the prefrontal cortex (Leao et al. 2015; Warren et al. 2016). Fos-expressing striatal ensembles were primarily DARPP32-containing medium spiny neurons of both D1 and D2 receptor types, along with small percentages of the different GABAergic interneurons (Leao et al. 2015; Rubio et al. 2015; Caprioli et al. 2017), again in line with the overall composition of the striatum. Future studies will be necessary to examine whether different electrophysiological alterations exist within different cell types of Fos-expressing neurons.

An additional consideration when comparing Fos-positive and Fos-negative neurons is to confirm that any electrophysiological differences result from the learning process and are not simply due to baseline differences in spontaneous activity of the neurons. To rule out this alternative explanation, a separate control group of animals should be tested with different set of cues or contexts than those used during learning and thus activate a set of Fos-expressing neurons different from those activated during learning.

\section{Functional engram formation during learning}

Although the idea that learning may be encoded in small populations of sparsely distributed neurons is not new, the tools to study these neuronal ensembles have only been recently developed. Given that this field is in its relative infancy, many questions remain to be answered. First, how are neurons selected to participate in a given ensemble? Most likely there is a population of neurons that happens to receive the highest numbers of activated cue-specific afferents that converge on what was an initially random pattern of neurons (Pennartz et al. 1994). Synaptic alterations are likely induced during subsequent training sessions so that the relevant cue-specific inputs can more reliably and efficiently activate the most strongly activated ensemble neurons (Koya et al. 2012; Yiu et al. 2014; Whitaker et al. 2016). This coupled with shifts in the intrinsic membrane properties of cue-selected ensemble neurons across training may lead to the selection of particular neurons as ensemble neurons (Whitaker et al. 2017; Ziminski et al. 2017, 2018). However, a different line of studies found that constitutive overexpression of the transcription factor CREB "before" learning or cue experience led to preferential recruitment of lateral amygdala neurons into an ensemble encoding cue-cocaine associations, or a "cocaine engram" (Hsiang et al. 2014). Subsequent work from the same laboratory found that constitutive CREB overexpression led to corresponding increases of excitability in lateral amygdala neurons, and that manipulating the level of excitability in LA changed the probability of neurons being incorporated into the ensemble (Yiu et al. 2014). They postulated that CREB-mediated increases of excitability may drive particular neurons to be incorporated into an ensemble. However, while transient CREB phosphorylation is probably an important step in forming engrams, it seems unlikely that neurons are allocated (e.g., via increased CREB function) for a particular memory prior to learning; the learning specific alterations cannot exist prior to cue-exposure and learning. To this point, Whitaker et al. (2017) measured excitability in Fos+ and Fos- neurons of the prefrontal cortex before and after operant training and found no difference in excitability in Fos+ and Fos- neurons on the first day of training, suggesting that neurons that go on to become part of the ensemble do not necessarily start at a higher baseline firing frequency or resting membrane potential. Nevertheless, these constitutive CREB overexpression studies support the idea that CREB may play an important role in the formation of naturally formed neuronal ensembles. Future studies are also necessary to determine whether naturally formed ensembles are selected differently based on brain region and cell type.

\section{Functional alterations in neuronal ensembles in other brain areas}

Although research is being done to characterize ensemble neurons relevant for drug addiction, much of this research is relegated to the nucleus accumbens or prefrontal cortex (Koya et al. 2012; Whitaker et al. 2016; Ziminski et al. 2017, 2018). While these two areas are known to be of critical importance in a number of addiction-related learned behaviors, other critical brain regions need to be examined. As mentioned, one study found that an ensemble in lateral amygdala may play a role in retrieval of a cocaine-related memory (Yiu et al. 2014), although this ensemble was induced by viral transduction prior to learning and cue exposure. It will be interesting to see if a naturally formed ensemble that is selected by cues during learning will also play a role in this memory. Recent studies indicate a role for the central amygdala (Venniro et al. 2017) and in particular neuronal ensembles in the central amygdala in mediating nicotine seeking (Funk et al. 2016) and alcohol dependence (de Guglielmo et al. 2016) in rats. Neuronal ensembles in the dorsal hippocampal CA1 region play a role in conditioned place preference to cocaine (Trouche et al. 2016). Neuronal ensembles in dorsomedial striatum have also been shown to mediate methamphetamine seeking (Caprioli et al. 2017). Thus, it will be important to assess functional electrophysiological alterations in these latter brain areas.

\section{Conclusion}

Identifying neurons that comprise activity-dependent ensembles has been a significant advancement in the past 10 years. The next step is to answer the question of "what is the engram." Given that it has been repeatedly shown that Fos-expressing neuronal ensembles play a causal role in the expression of learned behavior (Koya et al. 2009; Bossert et al. 2011; Fanous et al. 2012; Cruz et al. 2014; Pfarr et al. 2015; de Guglielmo et al. 2016; Funk et al. 2016; Warren et al. 2016; Caprioli et al. 2017; Whitaker et al. 2017), it is likely that the answer to this question involves the electrophysiological alterations that have been identified here (and in future studies) in Fos-expressing ensemble neurons. In addition to the electrophysiological alterations within the Fos-expressing neurons described above, a number of molecular alterations have also been identified only within Fos-expressing neuronal ensembles and not in the majority of neurons that are Fos-negative (Guez-Barber et al. 2011; Fanous et al. 2013; Liu et al. 2014; Li et al. 2015; Rubio et al. 2015, 2016). We now need to move past demonstrating causal roles for ensemble neurons per se and on to manipulations of identified alterations within these ensemble neurons to identify which specific electrophysiological and molecular alterations play causal roles in encoding the learned associations. With a focus on these long-lasting molecular and cellular alterations within the Fos-expressing neurons that are mediating behavior, we may finally elucidate the real engram and how it forms.

Although speculative, these findings could permit us to more accurately treat the maladaptive learned associations that drive addiction. There may be alterations that are relatively unique to drug addiction-related engrams that can then be targeted selectively within the relevant drug-associated ensembles. Alternatively, drug craving-related memory ensembles can be reactivated by 
drug-related cues, which puts these ensemble neurons in a unique highly activated state that distinguishes them from the surrounding less activated neurons. This high neural activity state creates new pharmacological targets such as activated NMDA receptor, which bind preferentially to ketamine and memantine when in the activated open state (Wood 2005; Johnson and Kotermanski 2006; Sinner and Graf 2008), or some pharmacological agents could bind selectively to activated MAP kinases within these activated ensemble neurons. This would add a new dimension of context-specific and ensemble-specific pharmacology to the more commonly used context-independent cell, receptor or neurotransmitter-targeted pharmacology.

\section{Acknowledgments}

We would like to acknowledge Marco Venniro for assistance in preparing the figure for the manuscript. This work was supported by the Intramural Research Program/National Institute on Drug Abuse/National Institutes of Health.

\section{References}

Barth AL, Gerkin RC, Dean KL. 2004. Alteration of neuronal firing properties after in vivo experience in a FosGFP transgenic mouse. J Neurosci 24: 6466-6475.

Bliss TV, Collingridge GL. 1993. A synaptic model of memory: long-term potentiation in the hippocampus. Nature 361: 31-39.

Bossert JM, Stern AL, Theberge FR, Cifani C, Koya E, Hope BT, Shaham Y. 2011. Ventral medial prefrontal cortex neuronal ensembles mediate context-induced relapse to heroin. Nat Neurosci 14: 420-422.

Bowers MS, Chen BT, Bonci A. 2010. AMPA receptor synaptic plasticity induced by psychostimulants: the past, present, and therapeutic future. Neuron 67: 11-24.

Brami-Cherrier K, Roze E, Girault JA, Betuing S, Caboche J. 2009. Role of the ERK/MSK1 signalling pathway in chromatin remodelling and brain responses to drugs of abuse. I Neurochem 108: 1323-1335.

Brown TE, Lee BR, Mu P, Ferguson D, Dietz D, Ohnishi YN, Lin Y, Suska A, Ishikawa M, Huang YH, et al. 2011. A silent synapse-based mechanism for cocaine-induced locomotor sensitization. J Neurosci 31: 8163-8174.

Buzsaki G. 2004. Large-scale recording of neuronal ensembles. Nat Neurosci 7: 446-451.

Cahill E, Salery M, Vanhoutte P, Caboche J. 2014. Convergence of dopamine and glutamate signaling onto striatal ERK activation in response to drugs of abuse. Front Pharmacol 4: 172.

Caprioli D, Venniro M, Zhang M, Bossert JM, Warren BL, Hope BT, Shaham Y. 2017. Role of dorsomedial striatum neuronal ensembles in incubation of methamphetamine craving after voluntary abstinence. J Neurosci 37: 1014-1027.

Carelli RM, Wightman RM. 2004. Functional microcircuitry in the accumbens underlying drug addiction: insights from real-time signaling during behavior. Curr Opin Neurobiol 14: 763-768.

Carelli RM, King VC, Hampson RE, Deadwyler SA. 1993. Firing patterns of nucleus accumbens neurons during cocaine self-administration in rats. Brain Res 626: 14-22.

Carelli RM, Ijames SG, Crumling AJ. 2000. Evidence that separate neural circuits in the nucleus accumbens encode cocaine versus "natural" (water and food) reward. J Neurosci 20: 4255-4266.

Cifani C, Koya E, Navarre BM, Calu DJ, Baumann MH, Marchant NJ, Liu QR, Khuc T, Pickel J, Lupica CR, et al. 2012. Medial prefrontal cortex neuronal activation and synaptic alterations after stress-induced reinstatement of palatable food seeking: a study using $c$-fos-GFP transgenic female rats. J Neurosci 32: 8480-8490.

Crombag HS, Bossert JM, Koya E, Shaham Y. 2008. Review. Context-induced relapse to drug seeking: a review. Philos Trans $R$ Soc Lond B Biol Sci 363: 3233-3243.

Cruz FC, Koya E, Guez-Barber DH, Bossert JM, Lupica CR, Shaham Y, Hope BT. 2013. New technologies for examining the role of neuronal ensembles in drug addiction and fear. Nat Rev Neurosci 14: 743-754.

Cruz FC, Babin KR, Leao RM, Goldart EM, Bossert JM, Shaham Y, Hope BT. 2014. Role of nucleus accumbens shell neuronal ensembles in context-induced reinstatement of cocaine-seeking. J Neurosci 34: 7437-7446.

Cruz FC, Javier Rubio F, Hope BT. 2015. Using c-fos to study neuronal ensembles in corticostriatal circuitry of addiction. Brain Res 1628: 157-173.

de Guglielmo G, Crawford E, Kim S, Vendruscolo LF, Hope BT, Brennan M, Cole M, Koob GF, George O. 2016. Recruitment of a neuronal ensemble in the central nucleus of the amygdala is required for alcohol dependence. J Neurosci 36: 9446-9453.

Disterhoft JF, Golden DT, Read HL, Coulter DA, Alkon DL. 1988. AHP reductions in rabbit hippocampal neurons during conditioning correlate with acquisition of the learned response. Brain Res 462: $118-125$.

Eichenbaum H. 2016. Still searching for the engram. Learn Behav 44: 209-222.

Engeln M, Bastide MF, Toulmé E, Dehay B, Bourdenx M, Doudnikoff E, Li Q, Gross CE, Boué-Grabot E, Pisani A, et al. 2016. Selective inactivation of striatal FosB/ $\Delta$ FosB-expressing neurons alleviates L-DOPA-induced dyskinesia. Biol Psychiatry 79: 354-361.

Faber ES, Delaney AJ, Sah P. 2005. SK channels regulate excitatory synaptic transmission and plasticity in the lateral amygdala. Nat Neurosci 8: 635-641.

Fanous S, Goldart EM, Theberge FR, Bossert JM, Shaham Y, Hope BT. 2012. Role of orbitofrontal cortex neuronal ensembles in the expression of incubation of heroin craving. J Neurosci 32: 11600-11609.

Fanous S, Guez-Barber DH, Goldart EM, Schrama R, Theberge FR, Shaham Y, Hope BT. 2013. Unique gene alterations are induced in FACS-purified Fos-positive neurons activated during cue-induced relapse to heroin seeking. J Neurochem 124: 100-108.

Feltenstein MW, See RE. 2013. Systems level neuroplasticity in drug addiction. Cold Spring Harb Perspect Med 3: a011916.

Funk D, Coen K, Tamadon S, Hope BT, Shaham Y, Le AD. 2016. Role of central amygdala neuronal ensembles in incubation of nicotine craving. J Neurosci 36: 8612-8623.

Garner A, Mayford M. 2012. New approaches to neural circuits in behavior. Learn Mem 19: 385-390.

Goldberg SR. 1976. Stimuli associated with drug injections as events that control behavior. Pharmacol Rev 27: 325-340.

Guenthner CJ, Miyamichi K, Yang HH, Heller HC, Luo L. 2013. Permanent genetic access to transiently active neurons via TRAP: targeted recombination in active populations. Neuron 78: 773-784.

Guez-Barber D, Fanous S, Golden SA, Schrama R, Koya E, Stern AL, Bossert JM, Harvey BK, Picciotto MR, Hope BT. 2011. FACS identifies unique cocaine-induced gene regulation in selectively activated adult striatal neurons. J Neurosci 31: 4251-4259.

Han JH, Kushner SA, Yiu AP, Cole CJ, Matynia A, Brown RA, Neve RL, Guzowski JF, Silva AJ, Josselyn SA. 2007. Neuronal competition and selection during memory formation. Science 316: 457-460.

Hebb DO. 1949. The organization of behavior; a neuropsychological theory. Wiley, New York.

Hopf FW, Bowers MS, Chang SJ, Chen BT, Martin M, Seif T, Cho SL, Tye K, Bonci A. 2010. Reduced nucleus accumbens SK channel activity enhances alcohol seeking during abstinence. Neuron 65: 682-694.

Hsiang HL, Epp JR, van den Oever MC, Yan C, Rashid AJ, Insel N, Ye L, Niibori Y, Deisseroth K, Frankland PW, et al. 2014. Manipulating a "cocaine engram" in mice. J Neurosci 34: 14115-14127.

Huang YH, Lin Y, Mu P, Lee BR, Brown TE, Wayman G, Marie H, Liu W, Yan Z, Sorg BA, et al. 2009. In vivo cocaine experience generates silent synapses. Neuron 63: 40-47.

Hyman SE, Malenka RC, Nestler EJ. 2006. Neural mechanisms of addiction: the role of reward-related learning and memory. Annu Rev Neurosci 29: 565-598.

Johnson JW, Kotermanski SE. 2006. Mechanism of action of memantine. Curr Opin Pharmacol 6: 61-67.

Kawashima T, Kitamura K, Suzuki K, Nonaka M, Kamijo S, TakemotoKimura S, Kano M, Okuno H, Ohki K, Bito H. 2013. Functional labeling of neurons and their projections using the synthetic activity-dependent promoter E-SARE. Nat Methods 10: 889-895.

Kawashima T, Okuno H, Bito H. 2014. A new era for functional labeling of neurons: activity-dependent promoters have come of age. Front Neural Circuits 8: 37 .

Koob GF. 2006. The neurobiology of addiction: a neuroadaptational view relevant for diagnosis. Addiction 101(Suppl 1): 23-30.

Kourrich S, Calu DJ, Bonci A. 2015. Intrinsic plasticity: an emerging player in addiction. Nat Rev Neurosci 16: 173-184.

Koya E, Golden SA, Harvey BK, Guez-Barber DH, Berkow A, Simmons DE, Bossert JM, Nair SG, Uejima JL, Marin MT, et al. 2009. Targeted disruption of cocaine-activated nucleus accumbens neurons prevents context-specific sensitization. Nat Neurosci 12: 1069-1073.

Koya E, Cruz FC, Ator R, Golden SA, Hoffman AF, Lupica CR, Hope BT. 2012. Silent synapses in selectively activated nucleus accumbens neurons following cocaine sensitization. Nat Neurosci 15: 1556-1562.

Lansink CS, Jackson JC, Lankelma JV, Ito R, Robbins TW, Everitt BJ, Pennartz CM. 2012. Reward cues in space: commonalities and differences in neural coding by hippocampal and ventral striatal ensembles. J Neurosci 32: 12444-12459.

Leao RM, Cruz FC, Vendruscolo LF, de Guglielmo G, Logrip ML, Planeta CS, Hope BT, Koob GF, George O. 2015. Chronic nicotine activates stress/ 
reward-related brain regions and facilitates the transition to compulsive alcohol drinking. J Neurosci 35: 6241-6253.

Lee BR, Dong Y. 2011. Cocaine-induced metaplasticity in the nucleus accumbens: silent synapse and beyond. Neuropharmacology 61: 1060-1069.

Lee BR, Ma YY, Huang YH, Wang X, Otaka M, Ishikawa M, Neumann PA, Graziane NM, Brown TE, Suska A, et al. 2013. Maturation of silent synapses in amygdala-accumbens projection contributes to incubation of cocaine craving. Nat Neurosci 16: 1644-1651.

Li X, Rubio FJ, Zeric T, Bossert JM, Kambhampati S, Cates HM, Kennedy PJ, Liu QR, Cimbro R, Hope BT, et al. 2015. Incubation of methamphetamine craving is associated with selective increases in expression of $B d n f$ and $T r k b$, glutamate receptors, and epigenetic enzymes in cue-activated fos-expressing dorsal striatal neurons. J Neurosci 35: 8232-8244.

Liu X, Ramirez S, Pang PT, Puryear CB, Govindarajan A, Deisseroth K, Tonegawa S. 2012. Optogenetic stimulation of a hippocampal engram activates fear memory recall. Nature 484: 381-385.

Liu QR, Rubio FJ, Bossert JM, Marchant NJ, Fanous S, Hou X, Shaham Y, Hope BT. 2014. Detection of molecular alterations in methamphetamine-activated Fos-expressing neurons from a single rat dorsal striatum using fluorescence-activated cell sorting (FACS). J Neurochem 128: 173-185.

Ma YY, Lee BR, Wang X, Guo C, Liu L, Cui R, Lan Y, Balcita-Pedicino JJ, Wolf ME, Sesack SR, et al. 2014. Bidirectional modulation of incubation of cocaine craving by silent synapse-based remodeling of prefrontal cortex to accumbens projections. Neuron 83: 1453-1467.

Marchant NJ, Kaganovsky K, Shaham Y, Bossert JM. 2015. Role of corticostriatal circuits in context-induced reinstatement of drug seeking. Brain Res 1628: 219-232.

Mayford M, Reijmers L. 2015. Exploring memory representations with activity-based genetics. Cold Spring Harb Perspect Biol 8: a021832.

Morgan JI, Curran T. 1986. Role of ion flux in the control of $c$-fos expression. Nature 322: 552-555.

Morgan JI, Curran T. 1991. Stimulus-transcription coupling in the nervous system: involvement of the inducible proto-oncogenes fos and jun. Annu Rev Neurosci 14: 421-451.

Morris RG, Anderson E, Lynch GS, Baudry M. 1986. Selective impairment of learning and blockade of long-term potentiation by an N-methyl-D-aspartate receptor antagonist, AP5. Nature 319: 774-776.

Mountcastle VB. 1957. Modality and topographic properties of single neurons of cat's somatic sensory cortex. J Neurophysiol 20: 408-434.

Moyer JR Jr, Thompson LT, Disterhoft JF. 1996. Trace eyeblink conditioning increases CA1 excitability in a transient and learning-specific manner. J Neurosci 16: 5536-5546.

Ngo-Anh TJ, Bloodgood BL, Lin M, Sabatini BL, Maylie J, Adelman JP. 2005. SK channels and NMDA receptors form a Ca2+-mediated feedback loop in dendritic spines. Nat Neurosci 8: 642-649.

Nicolelis MA, Fanselow EE, Ghazanfar AA. 1997. Hebb's dream: the resurgence of cell assemblies. Neuron 19: 219-221.

O'Brien CP, Ehrman RN, Ternes JW. 1986. Classical conditioning in human opioid dependence. In Behavioral analysis of drug dependence (ed. Goldberg S, Stolerman I), pp. 329-356. Academic Press, Orlando.

O'Keefe J. 1976. Place units in the hippocampus of the freely moving rat. Exp Neurol 51: 78-109.

Pennartz CM, Groenewegen HJ, Lopes da Silva FH. 1994. The nucleus accumbens as a complex of functionally distinct neuronal ensembles: an integration of behavioural, electrophysiological and anatomical data. Prog Neurobiol 42: 719-761.

Peters J, Kalivas PW, Quirk GJ. 2009. Extinction circuits for fear and addiction overlap in prefrontal cortex. Learn Mem 16: 279-288.

Pfarr S, Meinhardt MW, Klee ML, Hansson AC, Vengeliene V, Schonig K, Bartsch D, Hope BT, Spanagel R, Sommer WH. 2015. Losing control: excessive alcohol seeking after selective inactivation of cue-responsive neurons in the infralimbic cortex. J Neurosci 35: 10750-10761.

Pfarr S, Schaaf L, Reinert JK, Paul E, Herrmannsdorfer F, Rossmanith M, Kuner T, Hansson AC, Spanagel R, Korber C, et al. 2018. Choice for drug or natural reward engages largely overlapping neuronal ensembles in the infralimbic prefrontal cortex. J Neurosci 38: 3507-3519.

Ramirez S, Tonegawa S, Liu X. 2013a. Identification and optogenetic manipulation of memory engrams in the hippocampus. Front Behav Neurosci 7: 226.

Ramirez S, Liu X, Lin PA, Suh J, Pignatelli M, Redondo RL, Ryan TJ, Tonegawa S. 2013b. Creating a false memory in the hippocampus. Science 341: 387-391.

Ramirez S, Liu X, MacDonald CJ, Moffa A, Zhou J, Redondo RL, Tonegawa S. 2015. Activating positive memory engrams suppresses depression-like behaviour. Nature 522: 335-339.

Redondo RL, Kim J, Arons AL, Ramirez S, Liu X, Tonegawa S. 2014. Bidirectional switch of the valence associated with a hippocampal contextual memory engram. Nature 513: 426-430.
Reijmers LG, Perkins BL, Matsuo N, Mayford M. 2007. Localization of a stable neural correlate of associative memory. Science 317: 1230-1233.

Robinson TE, Berridge KC. 1993. The neural basis of drug craving: an incentive-sensitization theory of addiction. Brain Res Rev 18: 247-291.

Rubio FJ, Liu QR, Li X, Cruz FC, Leao RM, Warren BL, Kambhampati S, Babin KR, McPherson KB, Cimbro R, et al. 2015. Context-induced reinstatement of methamphetamine seeking is associated with unique molecular alterations in Fos-expressing dorsolateral striatum neurons. J Neurosci 35: 5625-5639.

Rubio FJ, Li X, Liu QR, Cimbro R, Hope BT. 2016. Fluorescence activated cell sorting (FACS) and gene expression analysis of fos-expressing neurons from fresh and frozen rat brain tissue. J Vis Exp. doi:10.3791/54358.

Russo E, Durstewitz D. 2017. Cell assemblies at multiple time scales with arbitrary lag constellations. Elife 6: e19428.

Schwindel CD, McNaughton BL. 2011. Hippocampal-cortical interactions and the dynamics of memory trace reactivation. Prog Brain Res 193: 163-177.

Scofield MD, Heinsbroek JA, Gipson CD, Kupchik YM, Spencer S, Smith AC, Roberts-Wolfe D, Kalivas PW. 2016. The nucleus accumbens: mechanisms of addiction across drug classes reflect the importance of glutamate homeostasis. Pharmacol Rev 68: 816-871.

Semon R. 1921. The mneme. George Allen, Unwin, London.

Siegel S. 1999. Drug anticipation and drug addiction. The 1998 H. David Archibald Lecture. Addiction 94: 1113-1124.

Sinner B, Graf BM. 2008. Ketamine. Handb Exp Pharmacol 182: 313-333.

Stewart J, de Wit H, Eikelboom R. 1984. Role of unconditioned and conditioned drug effects in the self-administration of opiates and stimulants. Psychol Rev 91: 251-268.

Suto N, Laque A, De Ness GL, Wagner GE, Watry D, Kerr T, Koya E, Mayford MR, Hope BT, Weiss F. 2016. Distinct memory engrams in the infralimbic cortex of rats control opposing environmental actions on a learned behavior. Elife 5: e21920.

Tonegawa S, Liu X, Ramirez S, Redondo R. 2015. Memory engram cells have come of age. Neuron 87: 918-931.

Trouche S, Perestenko PV, van de Ven GM, Bratley CT, McNamara CG, Campo-Urriza N, Black SL, Reijmers LG, Dupret D. 2016. Recoding a cocaine-place memory engram to a neutral engram in the hippocampus. Nat Neurosci 19: 564-567.

Venniro M, Caprioli D, Zhang M, Whitaker LR, Zhang S, Warren BL, Cifani C, Marchant NJ, Yizhar O, Bossert JM, et al. 2017. The anterior insular cortex $\rightarrow$ central amygdala glutamatergic pathway is critical to relapse after contingency management. Neuron 96: 414-427 e418.

Warren BL, Mendoza MP, Cruz FC, Leao RM, Caprioli D, Rubio FJ, Whitaker LR, McPherson KB, Bossert JM, Shaham Y, et al. 2016. Distinct fos-expressing neuronal ensembles in the ventromedial prefrontal cortex mediate food reward and extinction memories. J Neurosci 36: 6691-6703.

Warren BL, Suto N, Hope BT. 2017. Mechanistic resolution required to mediate operant learned behaviors: insights from neuronal ensemble-specific inactivation. Front Neural Circuits 11: 28.

Whitaker LR, Carneiro de Oliveira PE, McPherson KB, Fallon RV, Planeta CS, Bonci A, Hope BT. 2016. Associative learning drives the formation of silent synapses in neuronal ensembles of the nucleus accumbens. Biol Psychiatry 80: 246-256.

Whitaker LR, Warren BL, Venniro M, Harte TC, McPherson KB, Beidel J, Bossert JM, Shaham Y, Bonci A, Hope BT. 2017. Bidirectional modulation of intrinsic excitability in rat prelimbic cortex neuronal ensembles and non-ensembles after operant learning. J Neurosci 37: 8845-8856.

Wikler A. 1973. Dynamics of drug dependence. Implications of a conditioning theory for research and treatment. Arch Gen Psychiatry 28: 611-616.

Wilson MA, McNaughton BL. 1993. Dynamics of the hippocampal ensemble code for space. Science 261: 1055-1058.

Wood PL. 2005. The NMDA receptor complex: a long and winding road to therapeutics. Drugs 8: 229-235.

Yiu AP, Mercaldo V, Yan C, Richards B, Rashid AJ, Hsiang HL, Pressey J, Mahadevan V, Tran MM, Kushner SA, et al. 2014. Neurons are recruited to a memory trace based on relative neuronal excitability immediately before training. Neuron 83: 722-735.

Ziminski JJ, Hessler S, Margetts-Smith G, Sieburg MC, Crombag HS, Koya E. 2017. Changes in appetitive associative strength modulates nucleus accumbens, but not orbitofrontal cortex neuronal ensemble excitability. I Neurosci 37: 3160-3170.

Ziminski JJ, Sieburg MC, Margetts-Smith G, Crombag HS, Koya E. 2018. Regional differences in striatal neuronal ensemble excitability following cocaine and extinction memory retrieval in fos-GFP mice. Neuropsychopharmacology 43: 718-727.

Received June 12, 2018; accepted in revised form July 9, 2018. 


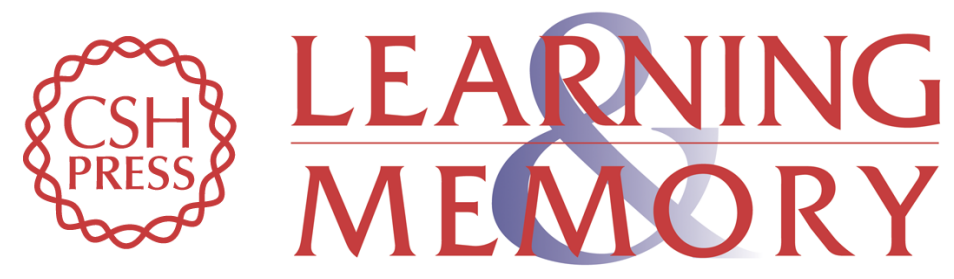

Chasing the addicted engram: identifying functional alterations in Fos-expressing neuronal ensembles that mediate drug-related learned behavior

Leslie R. Whitaker and Bruce T. Hope

Learn. Mem. 2018, 25:

Access the most recent version at doi:10.1101//m.046698.117

References This article cites 92 articles, 29 of which can be accessed free at: http://learnmem.cshlp.org/content/25/9/455.full.html\#ref-list-1

License This is a work of the US Government.

Email Alerting Receive free email alerts when new articles cite this article - sign up in the box at the Service top right corner of the article or click here. 